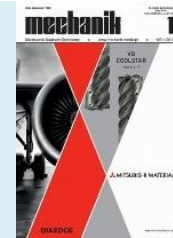

Author: Bogumił Jurkiewicz

Title of article: „Wykorzystanie środowiska ANSYS w obliczeniach uszczelnień elastomerowych w firmie WABCO Polska” (“Use of ANSYS environment in elastomer sealing simulations at WABCO Polska")

Mechanik, Vol. 91, No. 1 (2018): pages 91-93

DOI: https://doi.org/10.17814/mechanik.2018.1.23

\title{
Use of ANSYS environment in elastomer sealing simulations at WABCO Polska
}

\author{
Wykorzystanie środowiska ANSYS w obliczeniach \\ uszczelnień elastomerowych w firmie WABCO Polska
}

BOGUMIK JURKIEWICZ *

For pneumatic and electronic systems that are manufactured by WABCO Polska, it is extremely important to ensure tightness in a wide range of temperatures or dimensional tolerances and the service life of the sealing element. Presented is the way to verify dedicated elastomeric seals through structural analysis in ANSYS environment. The developed method was based on the example of the air distribution channel cover in one of valves of pneumatic braking system. Numerical results were verified by testing. KEYWORDS: elastomer seals, structural simulations

In the process of designing pneumatic devices - the production of which is the basic branch of WABCO's activity - tightness should be included in key indicators to which attention should be paid. For its assurance, elastomere seals with various geometric shapes depending on the place of their construction are the answer. Only some of them (like O-ring seals) can be selected by analytical calculations, using the DIN 3771-5 standard or a software based on it (e.g. M-Design). However, in the remaining, numerous cases, the selection of optimal sealing parameters is based on the results of numerical analyzes carried out using the finite element method.

\section{Verification of elastomeric sealing on the example of a butt seal}

To illustrate the seal simulation procedure, a sample of a butt-joint gasket and cross-sectional geometry was prepared allowing it to be mounted in one of the brake system valves, between the cover (which is also a complete solenoid valve) and the air distribution plate.

One of the first steps of numerical analysis, which often has a decisive influence on the quality of results and the possibility of their correct interpretation, is the selection of the material model. In practice, obtaining specific data for a particular elastomer can be difficult, especially under time pressure. Therefore, when analyzing existing seals, a gasket compression test is carried out on the strength machine (fig. 1), in which the dependence of reaction force on the distance traveled is recorded.

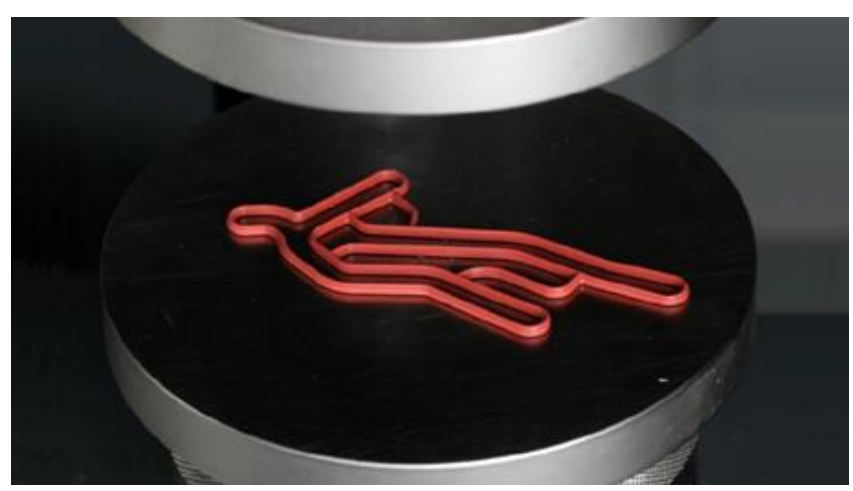

Fig. 1. Tested seal between plates of a durability machine (photo: Tomasz Pietrzak)

This non-linear relationship must be mapped by the behavior of the computational model (fig. 2), in which material model in the ANSYS environment is described using the Mooney-Rivlin parameters selected in an iterative manner.

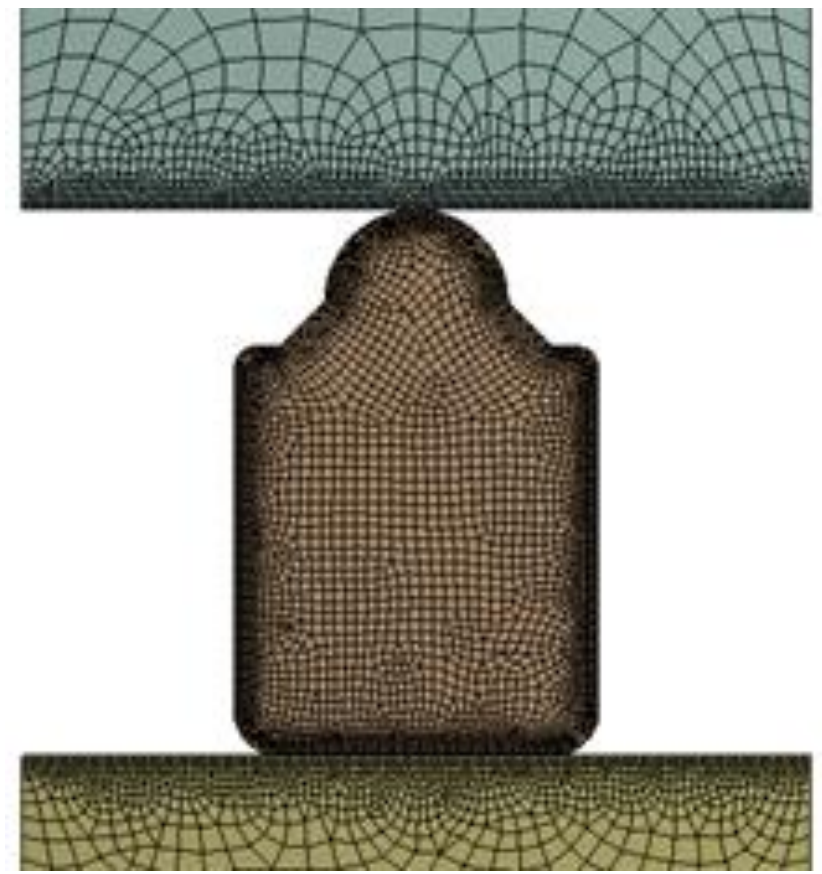

Fig. 2. Two-dimensional discrete model (flat deformation state) for verification of the material model 
Results of the total reaction force for MR parameters corresponding to the hardness 69 and 70 IRHD of the VMQ elastomer (according to WABCO databases) determined by multiplication of the result of the flat deformation and factor analysis resulting from the ratio of the contact surface corresponding to the $2 \mathrm{D}$ analysis and the $3 \mathrm{D}$ model, shown in the graph (fig. 3).

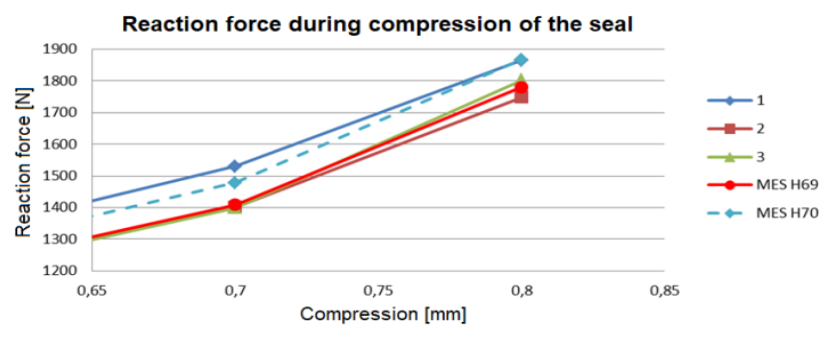

Fig. 3. Dependence of the reaction force during compression of the seal from the distance traveled

For further analyses, a material model was adopted, for which the results of the simulation reflecting the experiment were marked in red on the graph. The results for this material model correlate very well with the results of two of the three measurements. The first measurement is better reflected by the blue line (results for the material model corresponding to $70 \mathrm{IRHD}$ ), but from the point of view of the leak test, the results obtained from the simulation of a softer material (red line) will be critical.

\section{Results of numerical analysis of the seal}

As a result of the numerical analysis of the seal, the total reaction force was obtained with full compression of the sea at $2 \mathrm{kN}$, a high level of reduced relative deformation (65\%) and a large area of reduced relative deformation higher than $50 \%$ (fig. 4).

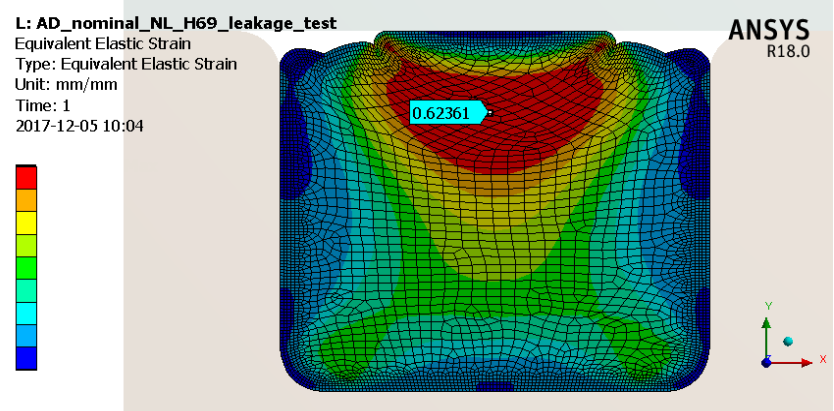

Fig. 4. Level of reduced relative deformations in the seal cross section after assembly

The high reaction force can in many cases lead to such phenomena as creep or plastic deformations in the components cooperating with the seal (these are more and more often made of plastics). The high level of relative deformation is, however, critical from the point of view of permanent elastomer deformation as a result of applying a constant load (deformation also visible after unloading).

Tightness of the connection was also analyzed. In the present case, the pressure level in the contact repeatedly exceeded the tightness test for the material used in WABCO. However, it is not the pressure in contact in an idealized, simulation case that is the most important. Often, attention should be paid to the decreases in compression due to the non-flatness of surface sealing, elastic deformation occurring under the influence of functional forces or permanent deformation as a result of aging at a high temperature. The susceptibility of the seal to these factors is examined by increasing the distance between the components of the sealing structure (fig. 5). In the discussed case, the risk of leakage loss occurs when the distance reaches $0.32 \mathrm{~mm}$, as illustrated in the graph (fig. 6).

It also turns out that the thermal expansion of the seal is too large to fill the groove at $80^{\circ} \mathrm{C}$ to not exceed $100 \%$. In such a situation, huge forces will act on the assembly, which may damage the device.

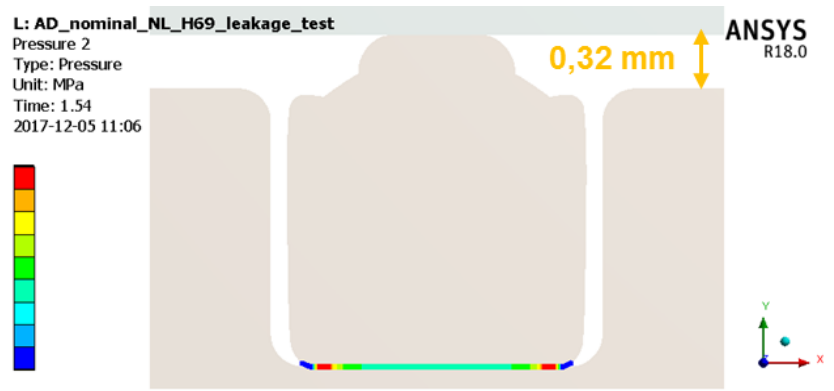

Fig. 5. Pressure in contact in the critical area of the seal

Pressure drop in contact when lifting the cover

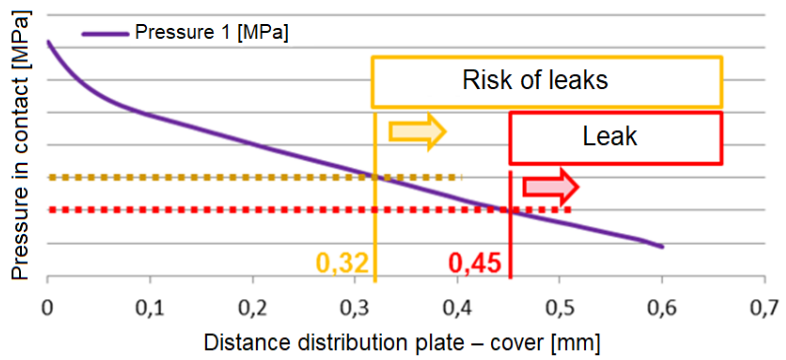

Fig. 6. Diagram of dependence of pressure in contact with the increase in distance between the components of the sealing structure

\section{Use of numerical analysis to verify changes in the cross section of the seal}

Numerical analyses accelerate the verification of the implemented construction changes. The changes were made based on the geometry of the cross-section of the tested seal and taking into account the results of the previously performed simulation. First of all, the height of the core of the seal, i.e. the rectangular cross-section similar to the rectangle, has been lowered. The effect of this was to reduce the relative deformation as well as to significantly improve the behavior under elevated temperature conditions. At the base of the seal, a groove was added to increase its resistance to loss of compression.

The simulation results of the modified seal indicate a nearly two-fold decrease in the reaction force after its assembly. The maximum level of relative distortion has dropped to $50 \%$, which means a reduction by almost $21 \%$ (fig. 7 ).

The contact pressure in the upper sealing area decreased compared to the original structure by approx. $30 \%$ and became lower than the pressure at its base, which increased significantly. Now the upper seal line has started to be crucial for the tightness and resistance to compression loss (fig. 8).

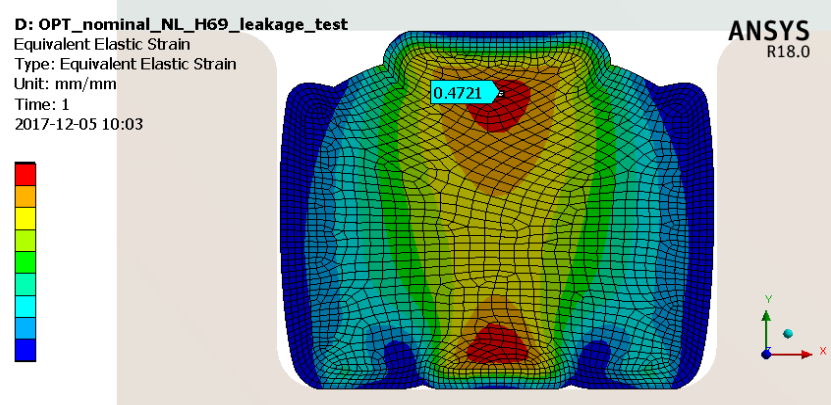

Fig. 7. Level of reduced relative deformations in the seal crosssection after its assembly 


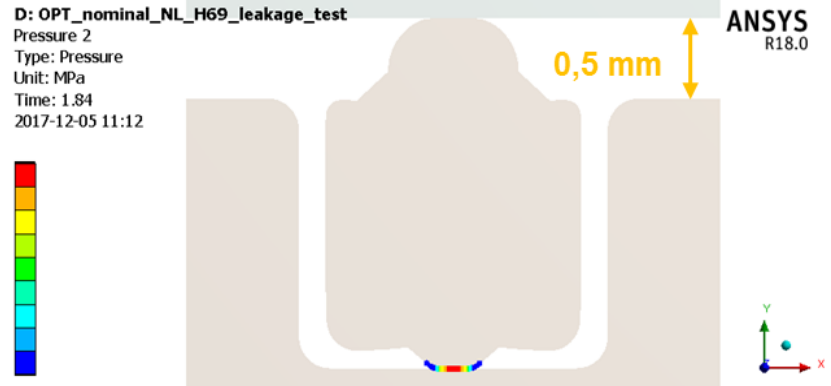

Fig. 8. Pressure in contact in the critical area of the modified seal

The modified seal shows much higher resistance to compression loss compared to the previously analyzed solution. This has been illustrated in the graph (fig. 9). The risk of loss of tightness after modification is much later - at $0.5 \mathrm{~mm}$ instead of $0.32 \mathrm{~mm}$ distance.

Pressure drop in contact when lifting the cover

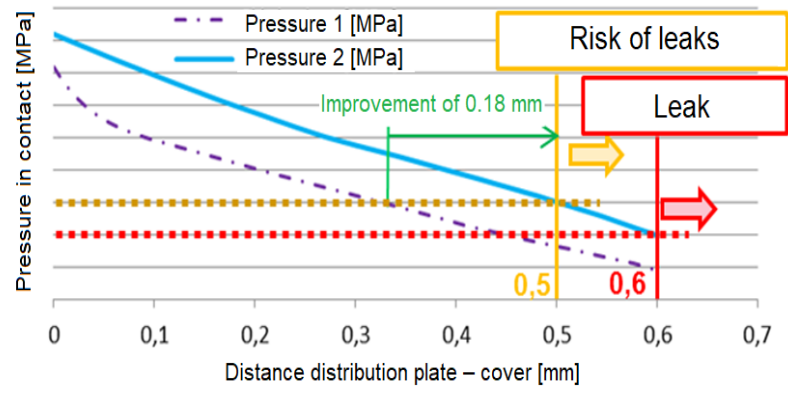

Fig. 9. Diagram of pressure dependence in contact with the distance increase between the elements of the original body (Pressure 1) and the modified (Pressure 2) seal

It has also been proven that under nominal conditions, the seal has enough space for expansion at elevated temperatures.

The proposed gasket was additionally subjected to analyzes under extreme conditions resulting both from dimensional tolerances and the operating temperature range.

\section{Verification of analyses by experiment}

The valve being an element of the pneumatic braking system was used to verify the presented analysis results. For its assembly, the following were used: the originally tested seal and the prototype of the modified seal.

As the verification was to be subjected to testing the sealability of the seals for the compression loss, a sufficient number of distance washers were inserted between the elements of the sealing (cover and distribution board) to ensure distance.

The test results together with simulation results are presented in the table. The distance between the parts where the leakage occurs and the risk of leakage is fully confirmed.

TABLE. Comparison of simulation results with the experiment - susceptibility of sealing to decrease of compression

\begin{tabular}{|c|c|c|c|c|}
\hline \multirow{2}{*}{$\begin{array}{c}\text { Lid- } \\
\text {-cover } \\
\text { distance }\end{array}$} & \multicolumn{2}{|c|}{ Primary seal } & \multicolumn{2}{|c|}{ Modified seal } \\
\hline & Experiment & Simulation & Experiment & Simulation \\
\hline $0.3 \mathrm{~mm}$ & No leak & $\begin{array}{c}\text { Risk of } \\
\text { leak }\end{array}$ & No leak & No leak \\
\hline $0.4 \mathrm{~mm}$ & Leak & Leak & No leak & No leak \\
\hline $0.5 \mathrm{~mm}$ & & & No leak & $\begin{array}{c}\text { Risk of } \\
\text { leak }\end{array}$ \\
\hline $0.6 \mathrm{~mm}$ & & & Leak & Leak \\
\hline
\end{tabular}

\section{Conclusions}

Simulation tools provide excellent opportunities to evaluate elastomer seals, often using time-saving methods of axis-asymmetrical analyzes or in a flat state of deformation.

Taking into account the quality of the results of the numerical analysis, a lot of attention should be paid to the most accurate deconstruction of the material model.

If it is not possible to carry out accurate material tests, simple squeezing tests of fragments of material or complete seals and based on them calibration of the material model come in handy.

Simulation of the seal requires referring not only to the nominal dimensions and room temperature, but also to a wide range of dimensional tolerances and thermal conditions as well as to the specifics of the parts that cooperate with the seal.

It should be remembered that the results of the seal simulation should also be taken into account when analyzing the remaining parts of the assembly, because a seemingly insignificant elastomer element can in extreme cases lead to the destruction of the cooperating plastics elements and even destructive effect on the metal parts.
Translation of scientific articles, their computer composition and publishing them on the website www.mechanik.media.pl by original articles in Polish is a task financed from the funds of the Ministry of Science and Higher Education designated for dissemination of science.

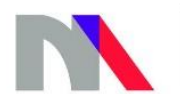

